\title{
Pregnancy and perinatal outcomes in women with polycystic ovarian syndrome
}

\section{A. Rizwana, Shery Angel Rajkumar*, C. R. Anuradha}

Department of Obstetrics and Gynecology, Chettinad Academy of Research and Education, Kelambakkam, Chennai, Tamil Nadu, India

Received: 26 August 2021

Revised: 06 October 2021

Accepted: 07 October 2021

\section{*Correspondence:}

Dr. Shery Angel Rajkumar,

E-mail: sheryangel@gmail.com

Copyright: (c) the author(s), publisher and licensee Medip Academy. This is an open-access article distributed under the terms of the Creative Commons Attribution Non-Commercial License, which permits unrestricted non-commercial use, distribution, and reproduction in any medium, provided the original work is properly cited.

\section{ABSTRACT}

Background: To study the pregnancy and perinatal outcomes in women with PCOS with normal women and to study the incidence of complications like menstrual irregularities, mode of conception, gestational diabetes mellitus, pre eclampsia, preterm labour and NICU admissions in women with PCOS.

Methods: It was prospective comparatives study done in 100 women to compare outcome in pregnancy with PCOS and normal women. A detailed history, general and obstetric examination, antenatal investigations, routine dating scan, glucose challenge test at 24 to 28 weeks in study and control groups, blood pressure recording and urine for proteinuria after 20 weeks to evaluate preeclampsia. After delivery, birth weight and APGAR score at 1 and 5 minutes were recorded. Body mass index was calculated and pregnancy outcome studied and compared.

Results: Out of 50 women with PCOS 13 developed GDM, 10 developed pre eclampsia, 6 had abortion, 4 went into preterm labour. 15 babies required NICU admission.

Conclusions: Pregnancy complications like GDM, pre eclampsia, preterm labour, abortions and neonatal complications like NICU admissions are higher in women with PCOS when compared with normal women. Hence PCOS needs to be diagnosed early and treated accordingly to prevent pregnancy complications.

Keywords: Gestational diabetes mellitus, Neonatal outcomes, Preeclampsia, Polycystic ovarian syndrome

\section{INTRODUCTION}

Polycystic ovarian syndrome is the most common hormonal disorder which affects around 5-8\% of women reproductive age group. ${ }^{1}$ It is associated with health problems later in life. PCOS affects females from puberty to menopause which presents with a variable clinical spectrum such as hyper androgensim, menstrual abnormalities, polycystic ovaries and metabolic abnormalities like diabetes mellitus, obesity and dyslipidemia. ${ }^{2}$ This term was first described by stein and levinthal. ${ }^{3}$ PCOS criteria was redefined by European society of human reproduction and embryology and the American society of reproductive medicine in 2003., Ultrasound criteria was added to increase the specificity of diagnosis. A polycystic ovary was defined as an ovary with
12 or more follicles measuring 2-9 $\mathrm{mm}$ in diameter and/or ovarian volume greater than $10 \mathrm{ml}$. According to Rotterdam criteria, PCOS is diagnosed when any two of the following three criteria are met: 1) irregular menstruation mainly oligomennorhea/ammenorhea, 2) hyprandrogenism (clinical or biochemical), 3) polycystic ovaries on ultrasound.

It is associated with infertility. Certain pregnancy complications are more common in PCOS women. Early pregnancy loss has been reported in 30 to $35 \%$ of women with PCOS. Hormonal abnormalities such as elevated LH, hyperandrogenism and abnormal progesterone production in PCOS women might explain higher pregnancy loss rate. Women with PCOS suffers mostly from infertility but when they conceive complications during pregnancy, 
delivery or postpartum for both the mother and the newborn needs to be studied.

Thus the objective of the study was to study the incidence of complications like spontaneous abortion, preterm labour, GDM, gestational hypertension, pre eclampsia and neonatal outcome in women with PCOS.

\section{METHODS}

This study was conducted in the department of obstetrics and gynaecology, Chettinad academy of research and education, Kelambakkam in 100 pregnant women attending the antenatal clinic satisfying the below mentioned criteria from November 2020 to April 2021. It was an observational study. The normal pregnant women who attended the antenatal clinic during the same period without medical illness like diabetes mellitus, hypertension and thyroid disorders were used as the control group $\left(\mathrm{P}_{1}\right)$.

\section{Inclusion criteria for the study group}

Inclusion criteria for the study group $\left(\mathrm{P}_{2}\right)$ were women with PCOS and age 18-40 years.

\section{Exclusion criteria for the study group}

Women with anovulation not due to PCOS, Women under 18 years or over 40 years of age, Women with obesity not due to PCOS, Women with hirsuitism due to adrenal or other causes, Women with other medical illness like hypertension and diabetes mellitus or thyroid disorders.

\section{Inclusion criteria for the control group}

Inclusion criteria for the control group $\left(\mathrm{P}_{1}\right)$ were women aged 18-40 years and women with normal menstrual history.

\section{Exclusion criteria for the control group}

Women with clinical signs of hyperandrogegism, PCOS in ultrasound, drug therapy, other medical illnesses like diabetes mellitus, hypertension, thyroid disorders, multiple pregnancy, previous history of gestational diabetes mellitus and hypertension.

Informed consent was obtained from all the patients. All patients in both the study and control group were subjected to detailed history taking like age, parity, menstrual, marital, past medical, family and personal history. In general examination height, weight, BMI, blood pressure, facial hair growth and presence of acne were noted.

\section{Outcomes studied}

Following outcomes were studied in both groups such as mode of delivery, preterm labour, abortion, APGAR score less than 7 in first minute and $5^{\text {th }}$ minute, NICU admission and birth weight.

Statistical analysis of the results done using SPSS software version 2.

\section{RESULTS}

A total of 100 pregnant women were studied out of which half of them had PCOS $\left(n=50, P_{2}\right)$ and the remaining were non PCOS patients $\left(n=50, P_{1}\right)$. In this study most of the cases were in the age group 24-29 years which was around $38 \%$ and was found to be statistically significant $\mathrm{p}=0.007$. Approximately $48 \%$ of women with PCOS were overweight, $26 \%$ were obese and was found to be statistically significant $(\mathrm{p}=0.002)$ between both study and control group.

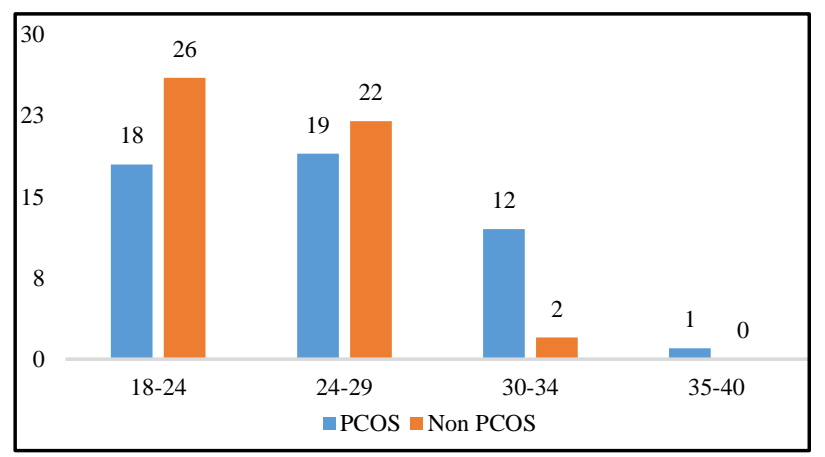

Figure 1: Age wise comparison of study participants.

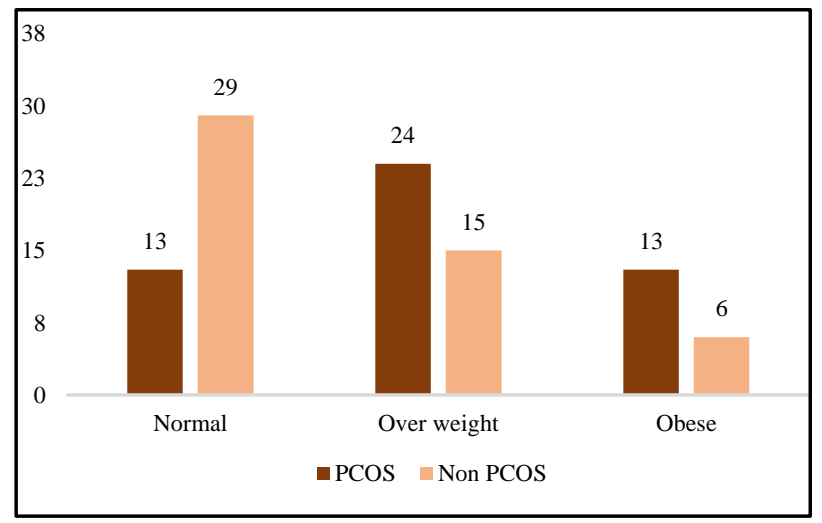

Figure 2: Association of BMI between study groups.

Majority of PCOS women around 60\% in the study group $\left(\mathrm{P}_{2}\right)$ had menstrual irregularities which was significantly higher than that reported among the control $\mathrm{p}=0.003$ (Figure 3). Out of 50 patients with PCOS $62 \%$ were primigravida and $38 \%$ were multigravida (Figure 4 ). In the study group (P1) 76\% got pregnant by spontaneous conception and $14 \%$ had ovulation induction and $10 \%$ underwent IVF conception, no significant difference was found $(\mathrm{p}=0.09)$ between the two groups regarding mode of conception (Figure 5). Ante-natal complications like gestational diabetes mellitus $(26 \%)$ pre eclampsia (20\%), abortion $(12 \%)$ and preteen labour $(8 \%)$ was not 
significant between study and control group with a $\mathrm{p}$ value of 0.3. Need for NICU admission was significantly higher in women with PCOS when compared with non PCOS women with $\mathrm{p}$ value of 0.04 .

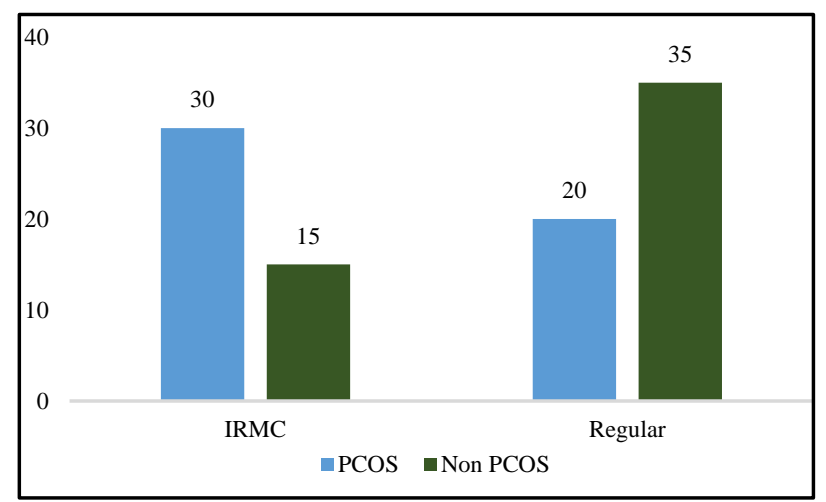

Figure 3: Comparison of menstrual abnormalities between study groups.

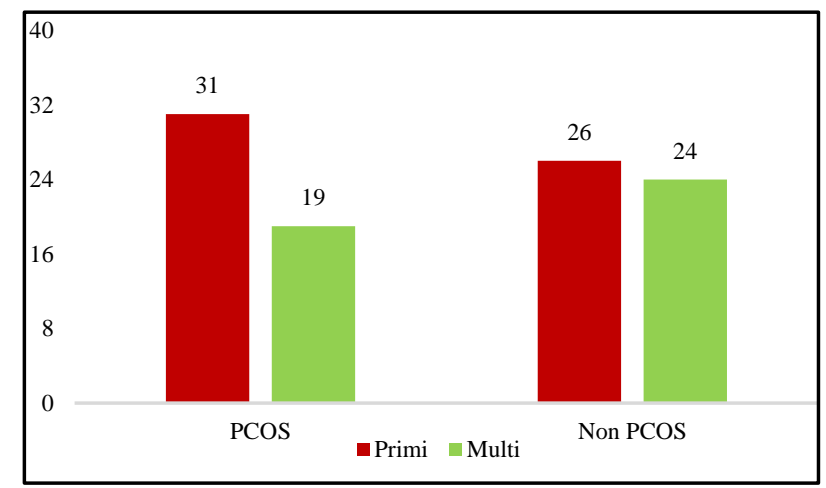

Figure 4: Comparison of parity between study groups.

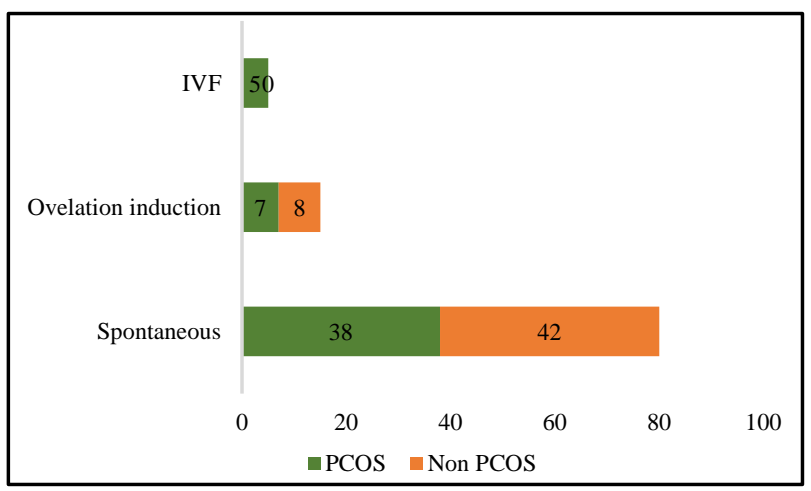

Figure 5: Comparison of method of conception between study groups

\section{DISCUSSION}

PCOS is the most common endocrine disorder in women of childbearing age. ${ }^{6}$ It is a most important risk factor for adverse outcome in pregnancy. ${ }^{7,8}$ However the impact of PCOS in pregnancy outcome both maternal and fatal outcomes are inconclusive and limited. ${ }^{9}$

\section{Pregnancy outcomes}

In current study $24 \%$ of women in the study group $\left(\mathrm{P}_{2}\right)$ got pregnant by assisted reproductive technology which is higher when compared to the study reported by Xiao et al in which only $3.9 \%$ of PCOS women had history of assisted reproductive techniques and ross et al reported $13.6 \%$ PCOS women conceived by ART. ${ }^{10,11}$

In this study spontaneous abortion was found to be $12 \%$ in PCOS women which was higher than that of Anwary et al, and was around $10 \%$ and lower than that of Wang et al who reported $27 \%$ of PCOS women had risk of abortion and Yan et al who reported $22.7 \%$ of PCOS women had one or more abortion history. ${ }^{12-14}$

$26 \%$ of pregnant PCOS women in the current study developed GDM, this when compare to that of Mikola et al who found only $20 \%$ PCOS women developed GDM, and according to Yan et al who found only $1.5 \%$ of PCOS women had GDM. And Xio et al found $18.2 \%$ of PCOS women developed GDM. ${ }^{15}$

In current study $20 \%$ of PCOS pregnant women developed pre-eclampsia, a finding which is higher than that of Bjercke et al who found $11.5 \%$ of PCOS group developed pre-eclampsia. $^{16}$

In this study $8 \%$ of PCOS group women had preterm labour which was relatively higher when compared to study by Boomsma et al. ${ }^{17}$

In this study 15 out of 50 babies which was around $30 \%$ born to women with PCOS required NICU admission and only 7 babies in normal group needed NICU admission. $\mathrm{P}$ value was found to be 0.04 showing NICU admission was higher in PCOS group.

The main limitation of this study was poor history from the patient and number of recruited women were small size and unavoidable selection bias which should be addressed in the future studies.

\section{CONCLUSION}

Many studies have proven that PCOS women has increased risk of developing PCOS complications like GDM, pre eclampsia, pre-term labour however in this study it was found that PCOS women were at high risk for menstrual irregularities, whereas no difference was found between both the groups in complications like GDM, preterm labour, pre eclampsia, abortion and need for NICU admission. Timely diagnosis and proper management at an early stage prevents pregnancy complications. Hence proper prenatal and antenatal care plays a very important role in preventing complications related to PCOS.

Funding: No funding sources Conflict of interest: None declared 
Ethical approval: The study was approved by the Institutional Ethics Committee

\section{REFERENCES}

1. Azziz R, Woods KS, Reyna R, Key TJ, Knochenhauer ES, Yildiz BO. The prevalence and features of the polycystic ovary syndrome in an unselected population. J Clin Endocrinol Metab. 2004;89:27459.

2. Franks S. Polycystic ovary syndrome. N Engl J Med. 1995;333:853-61.

3. Stein IF, Leventhal ML. Amenorrhea associated with bilateral polycystic ovaries. Am J Obstet Gynecol. 1935;29:181-91.

4. Revised 2003 consensus on diagnostic criteria and long-term health risks related to polycystic ovary syndrome. Fertil Steril. 2004;81:19-25.

5. Revised 2003 consensus on diagnostic criteria and long-term health risks related to polycystic ovary syndrome (PCOS). Hum Reprod. 2004; 19:41-7.

6. Fauser BC, Tarlatzis BC, Rebar RW, Legro RS, Balen $\mathrm{AH}$, Lobo R, et al. Consensus on women's health aspects of polycystic ovary syndrome (PCOS): the Amsterdam ESHRE/ASRM-Sponsored $3^{\text {rd }}$ PCOS Consensus Workshop Group. Fertil Steril. 2012;97(1):28-38.

7. Katulski K, Czyzyk A, Podfigurna-Stopa A, Genazzani AR, Meczekalski B. Pregnancy complications in polycystic ovary syndrome patients. Gynecol Endocrinol. 2015;31(2):87-91.

8. Falbo A, Rocca M, Russo T, D'Ettore A, Tolino A, Zullo F, et al. Changes in androgens and insulin sensitivity indexes throughout pregnancy in women with polycystic ovary syndrome (PCOS): relationships with adverse outcomes. J Ovarian Res. 2010;3(1):1-8.

9. $\mathrm{Yu}$ FH, Chen HS, Rao DP, Gong J. Association between polycystic ovary syndrome and the risk of pregnancy complications; a PRISMA-compliant systematic review and meta-analysis. Medicine. 2016;95:51.

10. Xiao Q, Cui YY, Lu J, Zhang GZ, Zeng L. Risk for gestational diabetes mellitus and adverse birth outcomes in Chinese women with polycystic ovary syndrome. Int J Endocrinol. 2016;2016:1-6.

11. Roos N, Kieler H, Sahlin L, Ekman-Ordeberg G, Falconer H, Stephansson O. Risk of adverse pregnancy outcomes in women with polycystic ovary syndrome: population based cohort study. BMJ. 2011;343.

12. Anwary SA, Alfazzaman M, Begum N. A clinical study on PCOS patients in a tertiary hospital. Med Today. 2009;22(1):34-7.

13. Wang JX, Davies MJ, Norman RJ. Polycystic ovarian syndrome and the risk of spontaneous abortion following assisted reproductive technology treatment. Hum Reprod. 2001;16(12):2606-9.

14. Yan X, Shi Y, Sheng Y, Tang R, Xu L, Li Y, et al. Pregnancy outcomes of patients with polycystic ovary syndrome undergoing in vitro fertilization and embryo transfer. Chin J Obstet Gynecol. 2011;46:923-7.

15. Mikola M, Hiilesmaa V, Halttumen M, Suhomen L, Tiitinen A. Obsteric outcome in women with polycystic ovarian syndrome. Hum Reprod. 2001;16:226-9.

16. Bjercke S, Dale PO, Tanbo T, Storeng R, Ertzeid G, Abyholm T. Impact of insulin resistance on pregnancy complications and outcome in women with polycystic ovary syndrome. Gynecol Obstet Invest. 2002;54:948.

17. Boomsma CM, Eijkemans MJ, Hughes EG, Visser GH, Fauser BC, Macklon NS. A meta-analysis of pregnancy outcomes in women with polycystic ovary syndrome. Hum Reprod Update. 2006;12(6):673-83.

Cite this article as: Rizwana A, Rajkumar SA Anuradha CR. Pregnancy and perinatal outcomes in women with polycystic ovarian syndrome. Int J Reprod Contracept Obstet Gynecol 2021;10:4232-5. 